\title{
El traslado del Congreso anfictiónico de Panamá al poblado de Tacubaya (1826-1828)
}

\author{
The transfer of the Panama Congress to the town of Tacubaya \\ (1826-1828)
}

GERMÁN A. DE LA REZA*

Rev. Bras. Polít. Int. 49 (1): 68-94 [2006]

\section{Introducción}

El traslado del Congreso anfictiónico de Panamá a la villa de Tacubaya en 1826 y las numerosas dificultades que enfrenta la instalación de la 'Asamblea americana' en México durante los siguientes dos años, forman uno de los episodios más oscuros del proyecto bolivariano de confederar a las repúblicas hispanoamericanas. A pesar de su prolongada duración y de constituir la etapa terminal del Congreso, gran parte de la literatura ignora el caso o le dedica menciones breves, a menudo inexactas. ${ }^{1} \mathrm{El}$ presente artículo busca reconstruir las condiciones decisionales que dieron lugar al fracaso de la Asamblea de Tacubaya. Se consideran las explicaciones vigentes de dicho desenlace, como la conformación de un sistema de repúblicas con énfasis en el equilibrio de sus independencias, y otras más circunstanciadas, como el rápido deterioro de la influencia bolivariana a partir de la Constitución vitalicia, la proliferación de conflictos de carácter interno y externo de las nuevas repúblicas, y la práctica desaparición de la amenaza de reconquista española. Sin embargo, en su mayoría están basadas en los acontecimientos del Congreso de Panamá y no tendrían porqué aplicarse al caso mexicano sino es luego del análisis específico.

La principal conjetura de este trabajo puede formularse en los siguientes términos: los vanos intentos de instalación de la Asamblea reportan un espacio analítico relativamente autónomo e importante para comprender las

\footnotetext{
* Professor e investigador de la Universidad Autónoma Metropolitana (UAM), México e Investigador de la Cátedra Simón Bolívar del Institut des Hautes Études de l'Amérique Latine, Universidad de Paris III, Francia (delareza@servidor.unam.mx).

El autor desea agradecer a la Biblioteca Latinoamericana de la Universidad de Tulane, el Archivo Nacional de Bolivia (Sucre), el Acervo Genaro Estrada de la Secretaría de Relaciones Exteriores de México y la Historical Society of Pennsylvania, por su valiosa cooperación.

${ }^{1}$ Notables excepciones son las obras de Cuevas Cancino, Francisco, Del Congreso de Panamá a la Conferencia de Caracas (Caracas, 1976), pp. 141-161, y Bierck, Harold A., Vida pública de Don Pedro Gual, (Caracas, 1983), pp. 315-328.
} 
limitaciones del proyecto bolivariano y su desenlace. Con el fin de substanciar esta hipótesis se consideran tres vertientes analíticas: las relaciones entre los ministros plenipotenciarios; la interlocución del Ejecutivo y las cámaras legislativas mexicanas respecto a la ratificación de los tratados de Panamá; y la actividad de los agentes diplomáticos estadounidenses. Para la reconstrucción del episodio de Tacubaya y de su cronología, se apela a las colecciones de documentos y correspondencia diplomática editadas por Raúl Porras Barrenechea y Oscar Barrenechea del Archivo Diplomático Peruano; Federico Gamboa, Antonio de la Peña, Francisco Cuevas Cancino y Ornán Roldán Oquendo del Archivo Histórico Diplomático Mexicano; William R. Manning del Departamento de Estado de Estados Unidos; José Rodríguez Cerna del Archivo de Guatemala, y los compendios de Daniel O’Leary y José María Restrepo de la correspondencia del Gobierno y los ministros grancolombianos. Algunas piezas poco conocidas o inéditas, que permiten completar y corregir datos publicados, provienen de la Biblioteca latinoamericana de la Universidad de Tulane; el Archivo Nacional de Bolivia; el Acervo Genaro Estrada de la Secretaría de Relaciones Exteriores de México; la Colección de Manuscritos de Poinsett de la Historical Society of Pennsylvania, y la Colección de documentos sobre el Congreso de Panamá del Foreign Office del Reino Unido. ${ }^{2}$

\section{Hipótesis del fracaso}

El escueto grupo de trabajos que atiende el caso de Tacubaya se concentra en su aspecto más notable: la recurrente imposibilidad de inaugurar la Asamblea en ese territorio. Según José María Tornel, contemporáneo de los acontecimientos en su calidad de secretario del presidente mexicano Guadalupe Victoria, el fracaso se debe a la reducida asistencia de los países miembros, así como al tiempo que debieron esperar los plenipotenciarios en Tacubaya. Pedro Zubieta, por su parte, otorga importancia a la 'resistencia pasiva sino hostil' de México hacia el proyecto bolivariano, conclusión que también acepta Jesús María Yepes. Manuel Medina Castro considera como causas el recelo con el que México ve a Colombia, incluyendo los supuestos designios imperiales de Simón Bolívar, además de la influencia desestabilizadora de Estados Unidos. Francisco Cuevas Cancino asocia factores objetivos y subjetivos; en un caso se trata del 'desbocamiento de las fuerzas centrífugas de los países hispanoamericanos, junto con la anarquía producto de los partidos que demandaban un lugar hasta entonces negado por los grandes caudillos independientes'; en el otro,

\footnotetext{
2 Referencias menos accesibles sobre la Asamblea de Tacubaya y su contexto nacional e internacional fueron facilitadas por el Centro de Investigación Parlamentaria del Congreso del Perú, el Archivo de la Cámara de Diputados de México, la Biblioteca del Congreso de Estados Unidos, la Embajada de los Países Bajos, la Biblioteca Central de México, la Biblioteca de la Universidad de Estocolmo y la Biblioteca de la Universidad Autónoma Metropolitana (Unidad Azcapotzalco).
} 
del convencimiento de Bolívar 'de la inutilidad de sus esfuerzos anfictiónicos' ${ }^{3}$ Obsérvese que el arraigado desinterés de los historiadores agrega a esta reseña un mensaje tácito: el episodio mexicano del Congreso anfictiónico carece de relevancia como objeto de estudio o, dicho en otros términos, representa un asunto menor dentro de una controversia más amplia.

Para la rectificación de este supuesto, el trabajo considera en primer lugar los preparativos del Congreso de Panamá y su realización. Con esto se persigue no sólo establecer el contexto, sino identificar los vínculos que asocian a tres grandes momentos del proyecto bolivariano: los tratados bilaterales de la Gran Colombia (Colombia), los acuerdos negociados en Panamá y la aventura mexicana.

\section{Antecedentes}

La tarea bolivariana de confederar a las nuevas repúblicas hispanoamericanas se inicia en 1819 con la creación de Colombia, y prosigue con la negociación y firma de cuatro tratados bilaterales de Unión, liga y confederación perpetua. Todos tienen por centro a este país; el primero se firma con el Perú el 6 de junio de 1822; el segundo con Chile el 23 de octubre de 1823; el tercero con México el 3 de diciembre de 1823 y, después de separarse del Imperio de Iturbide, el cuarto con Centroamérica el 15 de marzo de $1825 .{ }^{4}$ En varios sentidos, el texto y los alcances de estos acuerdos representan la piedra angular del Congreso anfictiónico e incluso de Tacubaya, donde operan como uno de los referentes legales de la presencia del os ministros hispanoamericanos. ${ }^{5}$ No sorprende que el 7 de diciembre de 1824, Bolívar apelara a las provisiones de estos tratados para convocar como Presidente del Perú, a los Gobiernos de Colombia, México, Provincias Unidas del Río de la Plata, Chile y, meses después, Centroamérica, a la celebración del Congreso anfictiónico. Al tiempo de solicitar el nombramiento de los respectivos ministros plenipotenciarios, recuerda el compromiso de 1822:

\footnotetext{
3 Tornel, José María, Breve reseña histórica de los acontecimientos más notables de la nación mexicana desde el año de 1821 hasta nuestros días (México, 1852); Zubieta, Pedro, Congresos de Panamá y Tacubaya: Breves datos para la historia diplomática de Colombia, segunda edición (Bogotá, 1926), p. 131; Yepes, Jesús María, Del Congreso de Panamá a la Conferencia de Caracas 1826-1954, Tomo I (Caracas, 1955), p. 116. Medina Castro, Manuel, Estados Unidos y América Latina, Siglo XIX (La Habana, 1968), p. 186. Cuevas Cancino, Del Congreso de Panamá, pp. 141-142.

${ }^{4}$ El Gobierno de Buenos Aires rechaza un tratado similar con Colombia y firma con el enviado colombiano un tratado de amistad el 8 de mayo de 1823, sin consecuencias sobre la anfictionía.

5 Obsérvese en este aspecto una objeción preliminar a la hipótesis, más ideológica que historiográfica, sobre la identidad hemisférica del proyecto bolivariano: la obra del Congreso se inicia y se fundamenta en una red de acuerdos exclusivamente hispanoamericanos.
} 
[Formar] una asamblea de plenipotenciarios de cada Estado 'que nos sirviese de consejo en los grandes conflictos, de punto de contacto en los peligros comunes, de fiel intérprete en los tratados públicos cuando ocurran dificultades, y de conciliador, en fin, de nuestras diferencias'. 6

Poco después, la convocatoria se extiende a la recientemente creada Bolivia, así como al Reino Unido y (por iniciativa del Vicepresidente colombiano, Francisco de Paula Santander) a Estados Unidos y el Brasil. Un hecho poco observado y que no está exento de implicaciones sobre la identidad hispanoamericana del proyecto, es que la presencia de Estados Unidos se limitaba a las negociaciones 'generales' de comercio, navegación y derecho internacional. Esto fue conocido por Henry Clay, Secretario de Estado norteamericano; Lucas Alamán, Canciller mexicano; George Canning, Canciller británico, así como el propio Santander. ${ }^{7}$

No obstante la inusitada cobertura geográfica de la convocatoria, de los once países que en algún momento anuncian su intención de enviar representantes, sólo cuatro los acreditan: el Perú, Colombia, México y Centroamérica. Inglaterra envía un observador y los Países Bajos un agente confidencial, mientras que Buenos Aires y Chile rechazan su participación, en el primer caso por celar del poderío bolivariano y en el segundo por una mezcla de adhesión nominal y abstención efectiva. ${ }^{8}$ Bolivia apenas alcanza a nombrar a sus ministros plenipotenciarios, José María Mendizábal y Mariano Serrano, no tanto por el poco tiempo que tiene de república independiente, sino por la renuncia de Casimiro Olañeta en noviembre de 1825 y la posterior indecisión de Serrano. ${ }^{9}$ En el caso de Estados Unidos, uno de sus representantes, John Sergeant llega al Istmo cuando las negociaciones habían concluido y el otro, Richard C. Anderson, fallece en Cartagena camino a Panamá. En el Brasil, finalmente, la percepción de una actitud antimonárquica en Hispanoamérica y el conflicto con Buenos Aires, mueven al Emperador Pedro I a cancelar la comisión de su plenipotenciario, Theodoro José Biancardi. ${ }^{10}$

\footnotetext{
${ }^{6}$ Simón Bolívar y José Faustino Sánchez Carrión, 7 de diciembre de 1824. Archivo Diplomático Peruano I (AP I), El Congreso de Panamá 1826, edición de Raúl Porras Barrenechea (Lima, 1930), pp. 3-6.

7 Clay a Anderson, 16 de septiembre de 1825, Diplomatic Correspondence of the United States Concerning the Independence of the Latin American Nations, seleccionada y arreglada por William R. Manning (Washington, 1930), Documento 145. Hurtado a Canning, 11 de enero de 1826, AP I, p. 363. Dawkins a Canning, 6 de junio de 1826, FO 97-115, 112

${ }^{8}$ De la Reza, Germán A., 'El Congreso anfictiónico de Panamá. Una hipótesis complementaria sobre el fracaso del primer ensayo de integración latinoamericana', Araucaria, vol. 5, no. 10 (Sevilla, 2003), pp. 90-95.

9 Archivo Nacional de Bolivia, Poder Legislativo, Leg. 103, ff. 28-27.

10 Sobre los motivos del Brasil para no atender el Congreso de Panamá, véase Bransi Aleixo, José Carlos, 'O Brasil e o Congresso Anfictiônico do Panamá', Revista Brasileira de Política Internacional, 43, no. 2 (Brasília, 2000), pp. 179-180.
} 


\section{Asamblea del Istmo}

Los primeros delegados en concurrir a Panamá son Manuel Lorenzo Vidaurre y José María Pando en junio de 1825. Su adelanto de seis meses con respecto a la llegada de cualquier otro ministro se explica por el plazo estipulado en la convocatoria, agosto o septiembre de 1825, atendida sólo por el Gobierno del Perú presidido por Bolívar. El 11 de diciembre arriban los representantes de Colombia, Pedro Gual y Pedro Briceño Méndez, con los cuales Vidaurre y Pando intercambian visitas e inician una serie de discusiones informales para conocer las posiciones de sus respectivos gobiernos. El 18 de marzo de 1826, desembarcan los centroamericanos Pedro Molina Mazariegos y Antonio Larrazábal y Arrivillaga. Dos semanas después llega Manuel Pérez de Tudela en reemplazo de Pando, nombrado por Bolívar Ministro de Relaciones Exteriores y, finalmente, el 4 de junio los mexicanos José Mariano Michelena y José Domínguez Manso. El primero de junio se les había unido el observador inglés Edward James Dawkins Esquire, ${ }^{11}$ mientras que el Coronel Jan Verveer, el enviado holandés, lo hace el 7 de julio, una semana antes del final de las negociaciones. ${ }^{12}$

Las conferencias se celebran en la sala capitular del Convento de San Francisco entre los días 22 de junio y 15 de julio de 1826 . Cada sesión es presidida de manera rotativa por los representantes de Colombia, Centroamérica, Perú y México. La agenda del Congreso, en gran parte definida por Bolívar, consta de diez puntos:

1. Renovación de los tratados de unión, liga y confederación;

2. Publicación de un manifiesto en que se denuncie la actitud de España y el daño que ha causado al Nuevo mundo;

3. Decidir sobre el apoyo a la independencia de Cuba y Puerto Rico, así como de las islas Canarias y Filipinas;

4. Celebrar tratados de comercio y de navegación entre los Estados confederados;

5. Involucrar a Estados Unidos para hacer efectiva la Doctrina Monroe en contra de las tentativas españolas de reconquista;

6. Organizar un cuerpo de normas de derecho internacional;

7. Abolir la esclavitud en el conjunto del territorio confederado;

8. Establecer la contribución de cada país para mantener contingentes comunes;

\footnotetext{
11 Dawkins desembarca en Chagres el 28 de mayo y llega a Panamá tres días después. Dawkins a Canning, 3 de junio de 1826, Foreign Office (FO), The National Archives, 97, 115, 109.

12 Verveer, Informe no. 4, 21 de julio de 1826. Buitenlandse Zaken, Geheime Stukken 1826. Las fuentes consignan equivocadamente el nombre del enviado holandés como Van Veer y Vervier.
} 
9. Adoptar medidas de presión para obligar a España al reconocimiento de las nuevas repúblicas; $y$

10. Establecer las fronteras con base en el uti possidetis de 1810.

Una vez instalada la Asamblea, primero se discute la propuesta de Dawkins de lograr la pacificación con España mediante reparaciones económicas. ${ }^{13}$ Luego de un debate que se extiende a tres conferencias, la Asamblea rechaza esta modalidad de armisticio y el Tratado de Unión, Liga y Confederación deja de hacer referencia a las iniciativas de paz con ese país. ${ }^{14}$ Otro de los objetivos de la agenda, lograr el necesario respaldo para liberar las islas de Cuba y Puerto Rico, también se elimina del Tratado para evitar que Estados Unidos se involucre en el Caribe español. Un caso especial representa la búsqueda de un acuerdo sobre límites. Centroamérica reclama a México el territorio de Chiapas y a Colombia las costas de Mosquitos; el Perú, a su vez, considera injusta la pérdida de Guayaquil y no reconoce el año 1810 como punto de partida para la aplicación del uti possidetis. Como los reclamos territoriales enconan los ánimos de los delegados, el Art. 22 transfiere el problema de las fronteras a 'las convenciones particulares' que los países establezcan en el futuro.

La Convención de Contingentes se presenta como la parte medular del proyecto en su versión defensiva. Negociada a partir de la quinta conferencia, sus artículos incorporan un conjunto de normas sobre la estructura militar, las aportaciones económicas y en tropas, así como los asuntos relativos al mando confederado. A pesar de las esperanzas puestas en su elaboración, el acuerdo termina siendo una alianza casi amistosa, con libre tránsito en los territorios confederados, modestas contribuciones por cada país y un mando todavía atomizado. La mayor parte del compromiso la asume México por su población más numerosa, mientras que en el otro extremo 'el Perú contribuye con nada a este ejército [...] y no está obligado a incrementar su marina.. 15

El establecimiento de una preferencia comercial hispanoamericana, otro objetivo importante, enfrenta dificultades insolubles desde el inicio de la Asamblea. Se conoce que la causa nominal es la falta de instrucciones de los ministros mexicanos, en lo cual es posible que influyera el fracaso de un acuerdo previo con Colombia ${ }^{16}$ y el que este último país desease adoptar los principios

\footnotetext{
13 Restrepo, José Manuel, Historia de la Revolución de la República de Colombia, Besanzón, 1858 (Medellín, 1970), vol. V, p. 271.

14 Tratado de Unión, Liga y Confederación de Colombia y México, Acervo Genaro Estrada de la Secretaría de Relaciones Exteriores de México (AM), 'Conferencias de Panamá y Tacubaya', LE. 869 I, ff. 9-11.

15 Dawkins a Canning, 17 de julio y 18 de julio de 1826, FO 97-115, 232 y 272.

16 'Tratado de comercio y navegación México - Colombia', 31 de diciembre de 1823. AM, LE. 869 I, años 1825-26, ff. 9-11.El Congreso mexicano lo ratifica 19 de febrero de 1824, pero Colombia anuncia su negativa a aprobarlo más de un año después, el 18 de abril de 1825. La diplomacia mexicana, Tomo I, Compilación de Federico Gamboa (México, 1910), pp. 263-266.
} 
comerciales promovidos por Estados Unidos. ${ }^{17}$ A estas razones Dawkins agrega otra menos conocida y que está relacionada con las condiciones climáticas del Istmo: los ministros prefieren posponer el acuerdo comercial para no exponerse a una estancia prolongada en Panamá. ${ }^{18}$ En conclusión, el artículo 25 del Tratado remite el asunto a las 'estipulaciones anteriores' y encarga a la siguiente Asamblea la tarea de fijar los derechos de comercio recíproco de los confederados.

Otro objetivo que fracasa es la creación de un mecanismo de arbitraje para resolver las disputas internas y externas de los aliados. El motivo de este rechazo de una de las funciones primordiales de la Confederación, lo conforma el deseo de los ministros de 'no interrumpir de modo alguno el ejercicio de la soberanía' de las nuevas repúblicas. Así, en lugar de la resolución de conflictos vía juicio de conciliación, el Art. 28 prevé la figura de 'mediación amistosa' y, en el caso de conflicto con otras naciones, la interposición de 'buenos oficios' de la Asamblea, además del impedimento de alianzas con países externos a la región sin el consentimiento del Congreso. Hacia el final de las conferencias, Colombia y México proponen que la Liga sea transitoria y que concluya con la guerra, luego de lo cual los tratados volverían a ser revisados.

\section{Valoración de los resultados}

Según Gual, los ministros colombianos sabían por conversaciones privadas que no les era posible concluir otros tratados que no fueran el de liga y de contingentes. Por ello, suplen 'este vacío insertando en [su] manuscrito todos aquellos artículos que no dejasen la negociación tan incompleta como quedó al fin'. El principal obstáculo, señala, es la mencionada 'falta de instrucciones en la mayor parte de los plenipotenciarios, particularmente de los de México. ${ }^{19}$ El informe de Briceño es más preciso; según él, se eliminaron siete artículos del preproyecto colombiano, aunque no totalmente, ya que unos fueron 'refundidos y su sustancia se halla en otros de los que constan en el trato'. ${ }^{20}$ Briceño también alude a la concentración de los ministros mexicanos en pactar la Convención de Contingentes, aunque por otros testimonios se sabe que los delegados colombianos no hicieron esfuerzos por distanciarse de esa estrategia. ${ }^{21}$

Sin duda, el juicio de Bolívar es más relevante para evaluar las discrepancias con el proyecto original. Éste figura en su acuse de recibo de los tratados,

\footnotetext{
17 Medina Castro, Estados Unidos y América Latina, p. 155.

18 Dawkins a Canning, 6 de julio de 1826, FO 97-115, 184.

${ }^{19}$ Gual al Secretario de Estado, Pedro Zubieta Congresos de Panamá y Tacubaya: Breves datos para la historia diplomática de Colombia, segunda edición (Bogotá, 1926).

20 Briceño al Secretario de Estado del Departamento de Relaciones Exteriores, 15 de agosto de 1826, O'Leary, Daniel, Memorias del General O'Leary, Tomo II (Caracas, 1830), pp. 531-541.

21 Según Vidaurre, ambas delegaciones (Colombia y México) fijan su atención en la creación de una escuadra. Vidaurre al Ministro de Estado, 23 de junio de 1826, AP I, pp. 387-388.
} 
donde observa que la Convención, en particular la aportación de cinco mil hombres por parte del Perú, es un implícito llamado a la invasión extranjera; para evitarla, exclama, sería necesario contribuir con el doble de tropas. Similares reparos le inspiran las normas sobre la artillería confederada y el Art. 10 sobre la caballería, 'incompatible con todos los principios del arte militar.' En su conjunto, el más detallado de los acuerdos, el militar, le parece 'inútil e ineficaz'. En cuanto al Tratado de Unión, Liga y Confederación, Bolívar advierte que su contenido 'puede embarazar la ejecución de proyectos [...] muy útiles y de gran magnitud'. En conclusión de su misiva, fechada en Guayaquil el 14 de septiembre, solicita a Briceño esperar a su llegada antes de proceder a la ratificación de los tratados. ${ }^{22}$ Poco antes, Bolívar había escrito al General Páez su más citada evaluación del Congreso de Panamá: "institución que debiera ser admirable si tuviera más eficacia, no es otra cosa que aquel loco griego que pretendía dirigir desde una roca los buques que navegaban. Su poder será una sombra y sus decretos consejos nada más". ${ }^{23}$

Conviene insistir en el hecho que, más allá de su mayor o menor apego al proyecto original, los tratados de Panamá imponen una versión minimalista de la Confederación. Reflejan más la búsqueda de protección de las soberanías dentro de un incipiente sistema hispanoamericano, que el refuerzo de una convergencia en trance de desaparición. Desde esa perspectiva, los tratados de Panamá convierten al Congreso en una instancia de compromisos ambiguos y auspician posteriores asambleas parcialmente privadas de su propósito original.

\section{¿Porqué Tacubaya?}

Sin embargo, estas resoluciones resultan anuladas por un acuerdo relativamente improvisado: el traslado de la Asamblea a la Villa de Tacubaya. La iniciativa, posible debido a la cautela con la que Bolívar propone a Panamá y a la recurrencia con que Santander invoca la insalubridad del Istmo, es precedida por un debate en el que el Perú propone a Quito, Centroamérica a Guatemala, México a Mérida (Yucatán) y Colombia prefiere mantener la sede en Panamá. ${ }^{24}$ La creciente preponderancia de México por su mayoritaria contribución a las fuerzas confederadas, le permiten atraer el Congreso cambiando a principios de julio su propuesta de Mérida por un suburbio de la Ciudad de México. ${ }^{25}$ Como resultado, el Art. 31 del Tratado de Unión, Liga

\footnotetext{
22 Simón Bolívar a Briceño, Guayaquil, 14 de septiembre de 1826. Obras completas, Compilación y notas de Vicente Lecuna, Segunda edición (La Habana, 1950), vol. II, pp. 469-470.

23 Bolívar a Páez, Ibidem pp. 456-457.

${ }^{24}$ Dawkins a Canning, 17 de junio de 1826, FO 97-115, 134.

25 Las instrucciones del 9 de marzo de 1826 sólo prevén el traslado a Yucatán. Archivo Histórico Diplomático Mexicano (AM I), El Congreso de Panamá y algunos proyectos de Unión Hispano-Americana, Prólogo de Antonio de la Peña y Reyes (México, 1926), p. 15.
} 
y Confederación estipula el traslado de la Asamblea a Tacubaya para continuar con las negociaciones pendientes.

Al conocer la noticia, Bolívar presiente que ese cambio pondrá la Asamblea 'bajo el inmediato influjo de [México], ya demasiado preponderante, y también bajo el de los Estados Unidos del Norte'. ${ }^{26}$ El Libertador no se engaña respecto a las consideraciones de poder y rivalidad detrás de ese acuerdo: William Tudor, Cónsul de Estados Unidos en Lima, comunica a su Gobierno en agosto de 1826 que el traslado obedece al recelo de México y Centroamérica por los planes de Bolívar. ${ }^{27}$ Tornel, estrecho colaborador del Presidente Guadalupe Victoria, comparte ese diagnóstico: "los plenipotenciarios escogieron a México para continuar sus sesiones, inducidos por el temor de no poder obrar con entera libertad en un lugar a donde alcanzara el prestigio del imperioso soldado". ${ }^{28}$

Sin embargo, los motivos oficiales apuntan en otra dirección y no sin sustento. Según el pormenorizado informe que el Gobierno mexicano envía a las Cámaras:

[Se hizo muy necesaria] la traslación de la Asamblea [...] por la insalubridad y absoluta falta de recursos que se experimentaba en el lugar designado, [así] como por la dificultad de comunicaciones con los respectivos Gobiernos y escasez de noticias de los acontecimientos de Europa [. En] cuatro meses que duramos ausentes, ni nosotros recibimos comunicación alguna de México, ni el Gobierno supo de nuestras operaciones a pesar de que por nuestra parte no se perdió ocasión alguna de participarlas [...]. La comunicación más frecuente en Panamá es [con Bogotá] y las cartas en ir y venir tardan setenta y cinco días a lo menos. ${ }^{29}$

Como lo había advertido Santander, la falta de salubridad se convierte en un problema mayor. A causa de la epidemia de 'vómito negro' (fiebre amarilla), el 14 de junio fallece James Le Mesurier y un mes después Leornard Childers, secretarios ambos de Dawkins. ${ }^{30}$ Según Briceño, esta dificultad es de tal magnitud que 'amenazaba inminentemente la vida de los ministros de México y Centro América, algunos de los cuales asistieron a las conferencias estando enfermos. ${ }^{31}$ En contrapartida, Tacubaya dispone de comunicación con los

\footnotetext{
26 Bolívar a Briceño, 14 de septiembre de 1826. Ibidem

27 Nota confidencial de William Tudor a Henry Clay, Lima, 24 de agosto de 1826, Manning, Diplomatic correspondence, Doc. 994.

28 Tornel, Breve reseña histórica, p. 49.

${ }^{29}$ Informe sobre la traslación del Congreso de Panamá a Tacubaya, comunicación de José Espinosa de los Monteros al Senado mexicano el 26 de septiembre de 1826. AM I, pp. 96-99.

30 Dawkins a Canning, 16 de junio y 16 de julio de 1826, FO 97-115, 125 y 229. Los plenipotenciarios ignoran que también Anderson fallece en su travesía de Bogotá a Cartagena y un año atrás su esposa. O'Leary, Memorias, II, p. 628; José M. Salazar a Henry Clay, Washington, 20 de noviembre de 1826, Manning, Diplomatic correspondence, Doc. 660; Pividal, Bolivar: Pensamiento precursor del antimperialismo, p. 225 .

31 Briceño Méndez al Secretario de Estado del Departamento de Relaciones Exteriores, 15 de agosto de 1826. O’Leary, Memorias, Tomo II, p. 539.
} 
importantes puertos de Veracruz y Acapulco; su relativo retiro no implica inconvenientes de provisión de víveres, escasos y de elevado precio en Panamá, ${ }^{32}$ tampoco de alojamiento, por sus mansiones, fuentes y amplios jardines. Según el plan inicial, las reuniones de la Asamblea debían realizarse en el edificio del Arzobispado y para residencia se dispuso la casa del Conde la Cortina, una de las más suntuosas del lugar. ${ }^{33}$

\section{Defección peruana}

Junto con el cambio de sede, los ministros acuerdan que uno de los delegados se dirija a su país con los tratados firmados y el otro integre la Asamblea en suelo mexicano. Esta medida abre las puertas a la defección del Perú, importante en el sentido de que desata las posibilidades del fracaso. Las causas del retiro peruano son múltiples; algunas de las más importantes estando relacionadas con sus reivindicaciones territoriales. Sobre su base y la crítica ideológica a la Constitución vitalicia, luego de la salida de Bolívar, este país adopta una política de restauración de su antigua preponderancia virreinal. Aunque infructuosa, esta estrategia se combina con la búsqueda de alianzas con Chile, Buenos Aires y Estados Unidos, dentro de un juego de equilibrios regionales y afectaciones recíprocas que anuncian la estructuración de un primer sistema interestatal en América.

Otro factor de la defección peruana, de menor importancia pero que involucra de manera directa al Congreso anfictiónico, es el comportamiento de Vidaurre. Contrariado en su propósito de diseñar las bases de la futura Confederación, el ministro peruano regresa a Lima para asociarse a grupos antibolivarianos y termina liderando la expulsión del ejército colombiano del Perú. Su enardecida lucha en contra de Bolívar no sólo se explica por el rechazo de su visión del Congreso. A partir de diciembre de 1825, Vidaurre recela de las intenciones de Gual respecto al Congreso y al Perú, ${ }^{34}$ actitud que se refuerza con el rechazo de la Asamblea por su arenga publicada de manera unilateral el 22 de junio en la Gaceta del Istmo. ${ }^{35}$

Pero la defección del Perú está sólo en sus primeras fases. Regresemos al momento cuando Vidaurre abandona Panamá y Tudela debe ir a Tacubaya. En agosto de 1826, Tudela se hace a la mar con Molina con destino a México. A poco de partir, una avería obliga al bergantín Tres Hermanas a encallar en

\footnotetext{
32 Restrepo, Historia de la Revolución de la República de Colombia, vol. V, p. 382.

33 Fernández del Castillo, Antonio, Tacubaya: Historia, leyendas y personajes (México, 1991), p. 225.

${ }^{34}$ Vidaurre y Pando al Ministro de Estado, 24 de diciembre de 1825, Archivo Diplomático Peruano (AP II), El Congreso de Panamá de 1826. Documentación inédita, Prólogo de Oscar Barrenechea y Raygada (Lima, 1942), pp. 82-94.

35 Vidaurre al Ministro de Relaciones Exteriores del Perú, Panamá, 23 de julio de 1826; Vidaurre a su esposa Francisca, 23 de junio de 1826, AP I, pp. 387-388 y 489.
} 
Punta Mala, donde ambos entablan una demanda contra su propietario. Sin esperar los resultados de esta gestión, Molina se dirige a Centroamérica por Conchagua. Tudela, por su parte, decide esperar en Panamá 'hasta que mejore la estación' ${ }^{36}$ y conduce el pleito en solitario. Transcurren seis meses, ocupados en alegatos y misivas en las que manifiesta a su Gobierno el deseo de esperar en Panamá a que Vidaurre regrese con los tratados ratificados. Durante gran parte de ese tiempo, el Gobierno del Perú lo hace en México. ${ }^{37}$ Sin embargo, cuando se entera de su situación, Pando autoriza el regreso el 20 de enero de 1827.38

Obra en el Archivo Diplomático Peruano una nota escrita por Vidaurre el 28 de febrero de 1827 en su calidad de nuevo Ministro del Interior y de Relaciones, en la cual felicita a Tudela por el 'modo como [...] se condujo en la importante legación de Panamá, por las instrucciones que le he dado sobre la materia'. ${ }^{39}$ No es posible saber a cuáles instrucciones se refiere, aunque es improbable que las diera como miembro influyente del gabinete antibolivariano de Andrés de Santa Cruz, ya que lleva en ese cargo sólo un mes. Días después, el 2 de marzo de 1827 Vidaurre refrenda su autoridad ordenando a José Agustín Arango, el secretario de la Legación peruana en Panamá, 'retirarse en la primera

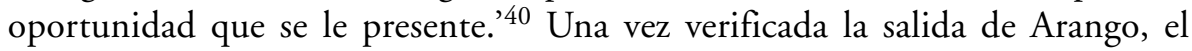
Perú queda sin representación alguna en la Asamblea americana.

\section{La espera de las ratificaciones}

Luego de una travesía sin contratiempos, Gual, Domínguez, Larrazábal y Michelena, desembarcan en Acapulco en agosto de 1826; Gual permanece en el puerto hasta enero de 1827 para atender a su esposa que acaba de dar a luz. ${ }^{41}$ Verveer llega a México en septiembre, mientras que Sergeant lo hace en enero de $1827 . .^{42}$ De Tudela todavía se dice que llegará en 'ocho o diez días'. Los otros plenipotenciarios, Briceño, Vidaurre y Molina, así como el observador inglés, se encaminan a sus respectivos países con los cuatro documentos aprobados en Panamá: el Tratado de Unión, Liga y Confederación Perpetua; un acuerdo sobre las condiciones de reunión y negociación de la Asamblea; la

\footnotetext{
36 Tudela a los ministros hispanoamericanos, 21 de agosto de 1826, AG, pp. 154-155.

${ }^{37}$ Los últimos pliegos de la Cancillería peruana dirigidos a Tudela enviados a México están fechados el 25 de noviembre de 1826. Larrazábal al Secretario de Estado, 20 de enero de 1827, AG, p. 173.

38 Tudela al Ministerio de Relaciones Exteriores del Perú, AP I, pp. 390-393, 394-396; Pando a Tudela, AP II, p. 66.

39 Vidaurre a Tudela, 28 de febrero de 1827, AP II, pp. 66-67.

40 Vidaurre a Arango, Lima, 2 de marzo de 1827, AP II, p. 67.

41 Larrazábal al Secretario de Estado, 20 de enero de 1827, AG, p. 173.

42 Larrazábal al Secretario de Estado, 23 de septiembre de 1826; 30 de diciembre de 1826; 10 de enero de 1827, AG, pp. 153,168 y 169.
} 
Convención de Contingentes, y un informe confidencial sobre asuntos estratégicos. ${ }^{43}$

Aunque los tratados no regulan específicamente el objeto de reunir a los plenipotenciarios antes del intercambio de las ratificaciones, para Molina y Larrazábal se trata de 'formar una Comisión Permanente que vaya preparando y adelantando los futuros trabajos y reciba la ratificación para su canje'. ${ }^{44}$ Este procedimiento, vago en su contenido, no tiene mayores respaldos. Por el contrario, la mayoría de documentos señala que la Asamblea no podía funcionar antes de que entraran en vigor los tratados que la instituían. Dawkins, interlocutor minucioso de los ministros hispanoamericanos, nos transmite una de estas evidencias, inserta en su informe a la Corona inglesa: 'el Congreso se reunirá cerca de [la Ciudad de] México después del intercambio de las ratificaciones. ${ }^{45}$ En enero de 1827, cuando Sergeant pregunta sobre el motivo por el cual no se sesiona en Tacubaya, Larrazábal contradice si primera interpretación:

[Se] verificará dicha reunión cuando se presenten en esta ciudad los otros ministros plenipotenciarios; que la llegada de estos ministros será después de que por los otros gobiernos de las respectivas repúblicas se verifique la ratificación de los tratados celebrados en Panamá. ${ }^{46}$

No son los únicos testimonios: este procedimiento es comunicado por Michelena a Sergeant el 19 de marzo de $1827^{47}$ y Poinsett lo había hecho a su Gobierno cinco meses atrás. ${ }^{48}$ Volveremos más adelante sobre este asunto y su importancia para la Asamblea de Tacubaya. Por lo pronto, Sergeant tiene la ocasión de explicar la posición de su Gobierno respecto al Congreso. De la voluminosa lista de instrucciones que le confía Henry Clay, cinco destacan por sus consecuencias para la Confederación. ${ }^{49}$ La primera es que Estados Unidos 'rechaza toda idea de un consejo anfictiónico investido con poderes para decidir las controversias entre los Estados americanos o para regular en cualquier forma su conducta'. En su lugar propone definir a las sesiones como encuentros libres sobre asuntos de seguridad, comercio y navegación. En materia comercial, la segunda instrucción, se prevé que el país 'sólo aceptaría que se celebraran tratados de amistad y comercio, sin que se pudieran conceder privilegios a nación alguna'.

\footnotetext{
43 'Concierto a que se refiere el artículo $2^{\circ}$ de la Convención de Contingentes', AP I, pp. 426-431.

${ }^{44}$ Larrazábal y Molina al Secretario de Estado, 1 de julio de 1826, AG, pp. 133-134.

45 Dawkins a Canning, (desde Londres) 15 de octubre de 1826, FO 97-115, 325.

46 Sergeant a Larrazábal, 16 de enero de 1827, Larrazábal a Sergeant, 19 de enero, AG pp. 170-172.

47 Sergeant a Michelena, 19 de marzo de 1827; Michelena a Sergeant, 24 de marzo, CUEVAS CANCINO, Del Congreso de Panamá, p. 143.

48 Poinsett a Clay, 6 de septiembre de 1826, American State Papers, Foreign Affairs, vol. 5, no. 443, p. 361.

${ }^{49}$ Instrucciones de Henry Clay, 8 de mayo de 1826, AM, LE. 877.
} 
Respecto a la posibilidad de hacer efectiva la Doctrina Monroe, Sergeant explica que, tratándose de una política de Estados Unidos, no entraña una estrategia de alianzas u obligaciones regionales, ni se opone a las posesiones que España aún tiene en América, Cuba y Puerto Rico. La cuarta, anticipada por Dawkins en Panamá y por las propias comunicaciones de Clay a los Gobiernos de México y Colombia, se resume a evitar que estos países intenten liberar dichas islas bajo el argumento de no entorpecer la tarea de mediación del Zar de Rusia. ${ }^{50}$ La última instrucción, bastante más conocida, es que Estados Unidos pretende 'mantener la neutralidad' en el conflicto con España, país al cual no cree capaz de reconquistar sus antiguos dominios americanos. Por estas aclaraciones cabe inferir que, en caso de haber asistido a las conferencias de Panamá, sus representantes hubieran necesitado sabotear el conjunto de la negociación hispanoamericana si es que se atenían a sus instrucciones.

Sin embargo, es difícil evaluar el impacto que tuvo la intervención de Sergeant en México. ${ }^{51}$ No sólo la mayor parte de sus instrucciones ya era conocida, sino que, al decir de Verveer, el delegado estadounidense parecía muy pobremente informado sobre los asuntos del proyecto. ${ }^{52}$ Pero no está solo; en febrero de 1827 Poinsett agrega a su condición de embajador en México la de flamante ministro plenipotenciario ante la Asamblea de Tacubaya. Como se verá más adelante, su presencia plantea un caso distinto al de Sergeant, que permanece en México sólo seis meses. ${ }^{53}$ Por lo pronto es necesario volver sobre el objeto central de la presencia de los plenipotenciarios en México: la aprobación de los tratados.

\section{Gestiones en las cámaras}

El proceso de ratificación se inicia con relativo optimismo el 14 de octubre de 1826, cuando el Presidente Guadalupe Victoria pasa los tratados al Congreso y ese día se informa a Larrazábal del beneplácito con el que son recibidos:

[Los tratados] los encuentran arreglados a los que esta misma República había celebrado con Colombia; a las instrucciones dadas a [...] Michelena y Domínguez, y a los intereses generales de las repúblicas confederadas, por que en su concepto debía darse la ratificación..$^{54}$

\footnotetext{
50 Clay a Salazar (ministro colombiano en Washington), 20 de diciembre de 1825; nota idéntica a la que Clay envía a Obregón (ministro colombiano en Washington) en la misma fecha, Manning, Diplomatic correspondence, Doc. 150.

51 No existe evidencia de tal encuentro, aunque es improbable que Sergeant no diera a conocer las instrucciones de su Gobierno a los ministros hispanoamericanos.

52 Verveer, Informe no. 13, 28 de febrero de 1827, Buitenlandse Zaken, Geheime Stukken 1826.

53 Sergeant anuncia el 2 de junio de 1827 que se retira de México y que la comisión en el Congreso Americano recae exclusivamente en Poinsett. Larrazábal al Secretario de Estado, 2 de junio de 1827, AG, pp. 192-193.

${ }^{54}$ Larrazábal al Secretario de Estado, 14 de octubre de 1826, AG, p. 156.
} 
Cuando el Congreso termina sus sesiones en diciembre sin haberlos aprobado, el ánimo no decae; se piensa que la ratificación intervendría a finales de enero del año siguiente. ${ }^{55}$ Larrazábal, atento a las opiniones del Congreso, se hace eco de esta confianza, aunque ya sabe que algunos diputados se oponen a resolver el caso mientras no se conozca el resultado de los conflictos intestinos de Centroamérica y Colombia. ${ }^{56}$ Un día antes del vencimiento del plazo para la ratificación (15 de marzo de 1827), el Congreso continúa revisando el Tratado con el Reino Unido. Larrazábal es informado de que inmediatamente después el Congreso se abocará al examen de los tratados de Panamá. ${ }^{57}$ Este supuesto también resulta equivocado: el 2 de abril, el Congreso descarta los tratados de Panamá por considerar que los Gobiernos de Colombia, Perú y Centroamérica ofrecen un panorama cambiante e incierto. Confundido, el ministro centroamericano declara que ya no puede ver con claridad el rumbo de la ratificación debido a la multiplicidad de opiniones en las cámaras. ${ }^{58} \mathrm{El} 11$ de abril rectifica: continúan las contradicciones del Congreso, pero ahora está convencido de que los tratados no se ratificarán. Esta presunción la basa en cinco elementos:

las demoras que este asunto ha sufrido, las que está sufriendo y sufrirá todavía, pues aún no se ha dado cuenta con el dictamen de la comisión, que según me han asegurado individuos de ella hace mes y medio que está extendido; la ninguna franqueza y el misterio que se nota en este punto; la poca importancia que se da a la alianza con unas repúblicas que suponen debilitadas y despedazadas por los partidos; el resfrío o indiferencia que generalmente se advierte; la ninguna noticia que se tiene de los ministros del Perú. ${ }^{59}$

Al ministro centroamericano le parece que el Congreso busca pretextos 'para disfrazar su intención y dorar su conducta,' y sentencia: 'todo me hace desconfiar de nuestra unión, en términos que no llegaré a creerla hasta no verla efectuada'. Como anticipado, el Congreso cierra sus sesiones el 21 de mayo de 1827 sin revisar los tratados. Cuando Victoria llama a un periodo extraordinario, sin fecha para su instalación, Larrazábal entiende que se trata de una iniciativa inútil. ${ }^{60}$

\section{Inestabilidad política y el Congreso mexicano}

Aquí es necesaria aclarar las condiciones política que encuentran los ministros en las cámaras mexicanas. El desinterés e incluso la oposición a la

\footnotetext{
55 Ibidem, 10 de enero de 1827, AG, p. 169.

56 Ibidem, 28 de febrero de 1827, AG, pp. 180-181.

57 Ibidem, 14 de marzo de 1827, AG, p. 182.

58 Ibidem, 4 de abril de 1827, AG, pp. 183-184.

59 Ibidem, 11 de abril de 1827. AG, pp. 184-185.

60 Ibidem, 12 de abril de 1827, AG, p. 189.
} 
ratificación de los tratados de Panamá, tienen como telón de fondo la pugna entre las logias yorkinas y la escocesa. Su importancia puede verse en el hecho de que impregna gran parte de los debates de la época, entre liberales y conservadores; federalistas y centralistas; republicanos y monárquicos; promotores del modelo estadounidense y defensores del británico; panamericanistas y hispanoamericanistas, incluyendo sus variantes y diferentes grados de maduración ideológica. Dirigidos en la sombra por Poinsett, los yorquinos abogan por un régimen liberal y federalista, cercano al modelo estadounidense; los escoceses se presentan como conservadores, proclives a la centralización y algunos de sus miembros comparten los ideales hispanoamericanistas.

En enero de 1827, la confrontación entre ambas facciones sube de tono a raíz del descubrimiento de un complot para restaurar el poder español. ${ }^{61}$ Este y otros sucesos estimulan el encono hacia la logia escocesa, asociada por los yorkinos a los intereses ibéricos. La presión del partido yorkino conduce a que los Estados de Jalisco, México, Guanajuato, Coahuila, Texas y el Gobierno federal decreten en ese año la expulsión de los españoles. ${ }^{62}$ Como reacción, el 23 de diciembre (tres días después de publicado el decreto federal) se produce el levantamiento del Vicepresidente Nicolás Bravo en Tulancingo. La pronta derrota de este líder de la logia escocesa y la expulsión del país de 17 a 42 miembros de su agrupación a mediados de 1828, dejan suponer un fuerte descalabro. No es así; en las elecciones presidenciales de septiembre de ese año, 137 diputados (o su equivalente, 11 votos legales) sufragan a favor del disidente yorkino Manuel Gómez Pedraza y sólo 123 por Vicente Guerrero (9 votos legales), el candidato de los yorkinos. ${ }^{63} \mathrm{El}$ descontento que produce este resultado entre estos últimos los lleva a promover el reemplazo del Presidente electo por Guerrero, lo cual sume al país en la anarquía. ${ }^{64}$

Aunque no se dispone de un diario de debates, es probable que en este contexto el asunto de la Confederación hispanoamericana ocupara un lugar menor en los debates de las cámaras. Concentradas en los asuntos cambiantes y complejos de la primera federación mexicana, son una principal caja de resonancia y un no menos importante componente de las rebeliones políticas. Naturalmente, esto no las exime de su responsabilidad en el fracaso de Tacubaya, pero ilustra las inconsecuencias y la falta de visión sobre el contexto

61 Esta sección sigue de cerca la cronología de Costeloe, Michael, La primera república federal de México 1824-1835 (México, 1996), pp. 137-247.

62 Entre 1827 y 1828, el número de españoles residentes en México disminuye en 27\%, con importantes variaciones según las entidades federativas: en el caso del Distrito Federal la reducción alcanza a $80 \%$. SIMS, Harold S., La expulsión de los españoles de México 1821-1836 (México, 1985), p. 231-232.

63 Costeloe, La primera república federal de México, p.182.

${ }^{64} \mathrm{La}$ asonada tampoco prospera; el Vicepresidente Bustamante socava la autoridad de Guerrero y en 1831 promueve su derrocamiento por incapacidad. 
internacional del poder legislativo. No sólo de México, sino también de Perú y Centroamérica en ese periodo y de toda Hispanoamérica en el siglo XIX. Recuérdese que las iniciativas de unión y confederación de Lima (1847-48), Santiago (1856-57) y nuevamente Lima (1864-65), se frustran en todos los casos como resultado de la no ratificación de los tratados. ${ }^{65}$

\section{Encuentro de Gual y Poinsett}

Junto con el primer desengaño en las cámaras, los ministros plenipotenciarios consolidan las tácticas que emplearán hasta el final de sus comisiones. La defendida por Gual consiste en reclamar la aprobación de los tratados como etapa previa a la instalación de la Asamblea; la instrumentada por Michelena y Domínguez sostiene a su vez que la ratificación debe ser uno de los temas de las conferencias formales. El primer procedimiento tiene una premisa sólida: la ausencia de ratificación de los tratados resta fundamento legal a la existencia del Congreso. ${ }^{66}$ Sin embargo, su reiterada invocación no es ajena al deseo de Gual de presionar al Gobierno de México en el asunto de los tratados y, al parecer, de poner límites al intervencionismo de Poinsett. Vayamos por partes.

Dado que la ratificación excluía al país del Norte por haber estado ausente de Panamá, Poinsett presiona en favor de abrir la Asamblea sin esperar y, muy probablemente, sin desear las ratificaciones. En abril de 1827, comunica a los ministros hispanoamericanos que él y Sergeant están 'prontos a concurrir al Congreso luego que se reúna. ${ }^{67}$ Hoy sabemos que Poinsett no solo estaba interesado en el establecimiento de acuerdos comerciales recíprocos, una de sus principales instrucciones, sino también en impedir que Hispanoamérica concediera ventajas comerciales a las potencias que todavía no la habían reconocido, Francia en particular. ${ }^{68}$ Como respuesta, Gual adelanta la necesidad de proteger los 'derechos e inmunidades' de los ministros y prefiere que se mantenga el procedimiento de espera. ${ }^{69}$ Una nota de Poinsett, conservada en el archivo de la Sociedad Histórica de Pennsylvania, transcribe los argumentos del ministro colombiano bajo un encabezamiento significativo: 'Las objeciones de Pedro Gual para la reunión del Congreso de Tacubaya'. ${ }^{70}$

\footnotetext{
65 De la Reza, Germán A., 'Antecedentes de la integración latinoamericana. Los congresos de unión y confederación del siglo IXI', Historia de América, no. 127 (2000), pp. 95-116.

${ }^{66}$ Larrazábal al Secretario de Estado, 31 de agosto de 1827, AG, p. 208.

67 Poinsett a Larrazábal, 30 de abril de 1827, AG, p. 188. Gual a Poinsett, 4 de mayo de 1827, Poinsett Papers vol. 4, Historical Society of Pennsylvania.

68 Poinsett a Clay, 16 de junio de 1827, Manning, Diplomatic correspondence, Doc. 914.

${ }^{69}$ Gual a Poinsett, 4 de mayo de 1827, Poinsett Papers.

70 Poinsett, 'Objections of Pedro Gual to meet the Congress at Tacubaya, 14 de abril de 1827'. Poinsett Papers.
} 
Con o sin razón, Gual sospecha que Poinsett está detrás del inmovilismo de las cámaras mexicanas. José Manuel Restrepo, el Secretario del Interior colombiano, señala de manera convergente que las logias yorkinas representan en esa época la plataforma de que dispone la campaña antibolivariana y la oposición a la anfictionía. ${ }^{71}$ No se descarta que los colombianos dispusieran de suficientes evidencias en esta materia; la fuerza de Poinsett en los congresos estatales, las cámaras de la Federación y en otras instituciones ${ }^{72}$ era bien conocida por Miguel de Santamaría, responsable de la Legación colombiana desde 1821 y cercano colaborador de Gual. ${ }^{73}$ Esto se refuerza con el hecho, más difundido, de su desacuerdo con el contenido del Concierto provisional, sobre todo porque incrementaba los riesgos de intervención hispanoamericana en Cuba. ${ }^{74}$ Sin embargo, cabe precisar que la intervención de Poinsett en los asuntos de México no apela al antibolivarianismo; al menos no con la intensidad de otros agentes estadounidenses, como Tudor en el Perú y William H. Harrison en Colombia.

\section{Otros agentes estadounidenses}

Tudor es cercano consejero del General La Mar y de su colaborador, Javier Luna Pizarro, aún antes de que el primero ascienda a la Presidencia del país y el segundo dirija el Congreso peruano. ${ }^{75} \mathrm{Su}$ conocida animadversión por Bolívar, sostenida incluso después de su traslado al Brasil en 1827, lo lleva a esperar que la destrucción de los proyectos de Bolívar (la Gran Colombia y el Congreso anfictiónico) elimine un futuro adversario de Estados Unidos. ${ }^{76}$ Una luz significativa sobre este agente la arrojan otros enviados extranjeros, en particular Thomas S. Willimott, Cónsul británico en el Perú. En noviembre de 1827 informa a su Gobierno que la hostilidad de 'algunos estadounidenses' hacia Bolívar - inequívoca referencia a Tudor - los hace lamentar abiertamente que allí donde había surgido un 'segundo Cesar', no hubiera surgido todavía

\footnotetext{
${ }^{71}$ Restrepo, Historia de la Revolución de la República de Colombia, vol. VI, pp. 232-233. Según Poinsett, su llegada a México ya existían cinco logias para las cuales pide cédulas a la Gran Logia de Nueva York. Aclaración de Poinsett, 4 de julio de 1827, Manning, Diplomatic correspondence, Doc. 916.

72 Según Tornel (Breve reseña histórica, p. 46), la multiplicación de los prosélitos del yorkismo llegó al extremo 'de dominar en el congreso general, especialmente en la cámara de diputados, en las legislaturas de los Estados, en sus gobiernos, en los cuerpos del ejército y en la mayor parte de las autoridades civiles y políticas'.

73 La acreditación de Santamaría ante el Imperio mexicano es firmada por Gual el 11 de octubre de 1821. La Diplomacia mexicana, p. 7. Otro funcionario de la Legación colombiana, Francisco Michelena y Rojas, señala que la administración de Victoria no es 'un gobierno mexicano [sino] el gobierno de Washington'. AM, LE. Legación de Colombia en México 1826-1831, s.f.

74 Poinsett a Clay, 21 de octubre de 1826, Department of State, Despachos desde México, II.

75 Sus misivas a Clay del 24 de agosto de 1826 y el 8 de enero de 1827 señalan la conveniencia de que La Mar y Luna Pizarro asuman un papel central en los destinos del Perú. Manning, Diplomatic correspondence, Doc. 994 y 996.

76 Tudor al Departamento de Estado, Lima, 3 de febrero de 1827.
} 
un 'segundo Brutus' ${ }^{77}$ El conflicto del Perú y Colombia propicia la coordinación de Tudor con Poinsett. En una nota confidencial del 20 de noviembre de 1827 dirigida a Clay y al embajador en México, Tudor informa que ha persuadido a La Mar para que solicite la mediación de Estados Unidos e Inglaterra en el conflicto bilateral. Imaginando hechos, afirma que 'el Perú está amenazado [de guerra] por Bolívar [y que] ha recibido información auténtica de las órdenes que [Bolívar] ha dictado para levantar en Guayaquil una fuerza para la invasión del Perú' ${ }^{78}$ Tiempo después, le sugiere a La Mar enviar copia de sus gestiones de mediación a Guadalupe Victoria (a través de Poinsett), entre otros jefes de Gobierno, con el argumento de que se trata de una causa de 'común interés para todas las nuevas repúblicas de este Continente'.

El otro agente diplomático que comparte la estrategia antibolivariana, Harrison, llega a Bogotá en 1829 precisamente con ocasión del conflicto con el Perú. Junto con el cónsul inglés, James Herderson, el primero atiza las ambiciones del General José María Córdoba y las discrepancias entre Francisco de Paula Santander y Bolívar. ${ }^{79}$ La revisión de su correspondencia permite afirmar que no obstante la brevedad de su comisión, estuvo vinculado a los disensos que acabarán con la unidad Colombia. En sus notas al Gobierno de Estados Unidos acusa a Bolívar de organizar personalmente la represión, el ajusticiamiento y el encarcelamiento de sus opositores; de haber inducido a Páez a rebelarse contra el Gobierno central; y de querer continuar la guerra contra el Perú luego de su victoria sobre este país en Tarqui. Una parte importante de sus comunicaciones las ocupa en exagerar la importancia del debate pro monárquico de Colombia y en referir los supuestos deseos de Bolívar de hacerse con la corona. ${ }^{80}$

Obsérvese que esta estrategia no es compartida por todos los agentes estadounidenses; Beaufort T. Watts, encargado de negocios interino en Bogotá, y John M. Foster, vice-cónsul en La Guayra, son ampliamente favorables a la integridad de Colombia. ${ }^{81}$ Dicho esto, no es menos verdad que el Gobierno estadounidense había cambiado de actitud respecto a Bolívar casi al mismo tiempo que la Asamblea americana se mudaba a Tacubaya y la Constitución

\footnotetext{
77 SELSER, Gregorio, Cronología de las intervenciones extranjeras en América Latina, Tomo I (México, 1994), p. 179.

78 Tudor a Clay, 20 de noviembre de 1827. Manning, Diplomatic correspondence, Doc. 1005.

${ }^{79}$ El descubrimiento de las relaciones de Herderson, Harrison y Torrens con Córdova y el que estos conocieran con anticipación la revuelta que este último prepara contra Bolívar parece ser el motivo principal por el cual Colombia pide el retiro de los tres representantes. Restrepo, Historia de la Revolución de la República de Colombia, p. 251.

${ }^{80}$ Harrison a Martin Van Buren, 145 de mayo de 1829 y 27 de mayo de 1829. Ibidem, Tomo II Parte 2, Doc. 684 y 687; además 688, 689 y 690 .

81 Sobre la actitud favorable a la integridad de Colombia de Watts y Foster, véase Manning, Diplomatic correspondence, Doc. 656, 657, 659, 665, 666, 670. Las iniciativas de Watts son recibidas con desagrado por Santander, de quien se queja al Gobierno de Estados Unidos y lo obliga a solicitar ausentarse de Colombia. Ibidem, Doc. 674, 675 y 677.
} 
vitalicia empezaba a adoptarse en el Perú. Un componente significativo de esta evolución son las instrucciones que Clay transmite a Sergeant y Poinsett el 16 de marzo de 1827, donde acusa a Bolívar de tener ambiciones monárquicos y de querer manipular al Congreso anfictiónico. ${ }^{82}$

\section{Comunicaciones oficiales entre los plenipotenciarios}

El 22 de junio de 1827, aniversario del Congreso de Panamá, Michelena y Domínguez envían su primera nota oficial a Gual y Larrazábal. El objetivo es saber, con independencia de lo que acontezca en el Congreso mexicano, si los delegados están dispuestos y habilitados para continuar con las conferencias anfictiónicas. Según reza la misiva:

para decidirse a [inaugurar la Asamblea, el Gobierno de México] necesitará instruirse previamente si los Plenipotenciarios que residen en esta capital se hallan suficientemente habilitados y en disposición de reunirse, y continuar las conferencias en la Asamblea. ${ }^{83}$

En su respuesta del día siguiente, Gual empieza reclamando que sea la primera comunicación que reciba desde su llegada a México y que por su fecha haya rebasado el plazo acordado en Panamá para la ratificación de los tratados. Enseguida observa que las dudas sobre la suficiente acreditación de los ministros son una señal de que México 'o desaprueba o deja en suspenso las demás estipulaciones acordadas solemnemente en el Istmo'. ${ }^{84}$ En final inquiere si aún es posible la reunión de los plenipotenciarios en Tacubaya y cuál su objeto en ausencia de dicha ratificación. Larrazábal también remite su respuesta de inmediato, aunque se limita a aclarar que está suficientemente habilitado en virtud de los poderes conferidos por su Gobierno en febrero de $1826 .{ }^{85}$

La segunda nota de Michelena y Domínguez a Gual, fechada el 27 de junio, abulta la controversia. Ambos critican que el ministro colombiano:

no se ha servido darnos una contestación precisa cual deseábamos y creemos que para tal reserva tendrá algún motivo poderoso y que el Gobierno de Colombia pulsará tal vez en el día [los] inconvenientes [de esa actitud] para realizar la reunión de la Asamblea y continuación de las conferencias. ${ }^{86}$

\footnotetext{
82 Clay, Instrucciones a Sergeant y Poinsett, 16 de marzo de 1827, Washington, AM, LE. 877; Entrada del día 17 de febrero de 1830, Memoirs of John Quincy Adams, edición de C. F. Adams, Tomo VIII (Filadelfia, 1874-1877), p. 190.

83 Michelena y Domínguez a Gual, 22 de junio de 1827. AM I, pp. 110-111.

${ }^{84}$ Gual a Michelena y Domínguez, 23 de junio de 1827. AM I, pp. 111-113.

85 Larrazábal a Michelena y Domínguez, 23 de junio de 1827. AM I, pp. 113-114. En nota dirigida a su Gobierno, el ministro centroamericano se muestra en desacuerdo con Gual; entiende que exige 'una especie de garantía sobre la ratificación de los tratados. Es claro que ni el señor Gual tiene derecho para exigir tal cosa, ni los otros autorización para prestarse a ella'. Larrazábal al Secretario de Estado, 24 de julio de 1827, AG, p. 202.

${ }^{86}$ Michelena y Domínguez a Gual, 27 de junio de 1827. AM I, pp. 114-116.
} 
Según esta misiva, la única prerrogativa que el convenio de Panamá agrega a las establecidas en el tratado bilateral y que México no había cumplido aún era el libre franqueo de la correspondencia de los ministros. El párrafo final es cercano a la tesis de Poinsett; los ministros se declaran convencidos de que Gual no desea la apertura de la Asamblea. La réplica de este último, remitida también al día siguiente, rechaza 'que la libertad de las correspondencias [haya sido] la única prerrogativa adicionada en Panamá a las comprendidas en el Tratado de 1823' ${ }^{87}$ Casi todos los artículos negociados en Panamá, señala, 'contienen reglas especiales y tan peculiares, que no era dable se hubiesen tenido presentes al tiempo de la firma [del tratado bilateral]'. Al cabo de este intercambio, el 5 de julio Michelena y Domínguez informan al Presidente Victoria sobre la 'disposición y suficiente autorización' de Larrazábal, y de los 'obstáculos' que Gual pone a sus requerimientos. ${ }^{88}$

No deja de ser insólito el tono de estas comunicaciones. Amén de las noticias llegadas del sur sobre los problemas internos de Colombia y la pérdida de influencia del Libertador en Bolivia y el Perú, es probable que la actitud del Gobierno mexicano estuviera influida, al menos en parte, por los informes que recibe de su Encargado de Negocios en Colombia, José Anastasio Torrens, en funciones entre 1824 y 1828 . Elaboradas en ocasiones en forma de diario, sus crónicas contienen una afanosa lista de insidias. Acusa a Bolívar de querer crear un partido favorable a sí mismo en México y de desear "un trastorno en [ese país] para probar que las instituciones republicanas no sólo no convienen a Colombia sino a ningún Estado americano." Recomienda a su Gobierno que vigile a los colombianos que hay en México, sobre todo a los que mantienen contactos con Bolívar "u otras personas de Colombia. ${ }^{89}$ En particular, atribuye a Gual el no ser "amigo de las instituciones liberales, y [de que] podría ser un agente para tratar de causar trastornos". ${ }^{90}$ Aunque la posición de Torrens no tiene efecto en Colombia, es posible que el Gobierno de México las considerara con mayor seriedad por tratarse de una fuente de información directa y por coincidir con la campaña de los adversarios de Bolívar, ahora preponderantes en América.

No obstante, a partir de la nota del 19 de julio, las comunicaciones mexicanas son más conciliadoras y francas. Por lo pronto, la primera misiva da seguridades a Gual de que México 'observará las estipulaciones contenidas en el convenio de Panamá y que habiéndose resuelvo el asunto de su habilitación

\footnotetext{
87 Gual a Michelena y Domínguez, 28 de junio de 1827. AM I, pp. 116-118.

88 Michelena y Domínguez al Gobierno de México, 5 de julio de 1827. AM I, pp. 118-19.

89 Nota reservada de José Anastasio Torrens, Bogotá, 3 de julio de 1828, AM, LE. 16699 (III), ff. 83-87.

90 Nota de Torrens, Bogotá, 14 de noviembre de 1827, LE. 1699 (III), f. 74 . El activismo de Torrens conduce a que Colombia solicite su retiro el 14 de julio de 1829. Estanislao Vergara al Ministro de Estado de México, Bogotá, 14 de julio de 1829, AM, LE. Legación de México y Ministros de Relaciones Exteriores de México y Santo Domingo 1825-1875, ff. 24.
} 
(el Gobierno decide ampararla en el Tratado bilateral de 1823, en particular el Art. 16), era posible inaugurar la Asamblea. ${ }^{91}$ La nota prosigue enumerando tres elementos de la posición mexicana: primero, la ratificación de los tratados no es un asunto exclusivamente mexicano; segundo, la Asamblea de Tacubaya no depende de los tratados de Panamá sino de los preexistentes, y por último, el tema de la ratificación debe ser uno de los objetos de las conferencias.

\section{Un intento de mediación confederada}

En un giro sorpresivo, en agosto de 1827 el Presidente mexicano aprueba el presupuesto para la Asamblea, instruye a Michelena su instalación a la brevedad y poco después los ministros mexicanos se mudan a Tacubaya. El objetivo que anima a Victoria en esta coyuntura es la solicitud centroamericana de mediación en la guerra civil que aqueja a ese país. ${ }^{92}$ Se comunica esta propuesta a los ministros hispanoamericanos ${ }^{93}$ y Larrazábal procede a su vez a pedir las instrucciones de su Gobierno para participar en las conferencias de la Asamblea. ${ }^{94}$ Sin embargo, Gual (y al final también Larrazábal) prefiere comenzar las tratativas en una reunión previa e informal. ${ }^{95}$ Como respuesta, Michelena y Domínguez deciden pedir autorización a su Gobierno.

No sin razón, Larrazábal ve en esa solicitud una falta de consecuencia, ya que el encuentro previsto por Gual 'nunca tendría otro carácter que el de la conversación de cuatro amigos', y si Michelena y Domínguez tenían autorización para instalar la Asamblea, más la tendrían para asistir a una reunión conducente a ella. ${ }^{96}$ Sin embargo, cabe conjeturar que la conferencia informal contrariaba el proyecto de Victoria de instalar la Asamblea en un plazo breve. Asimismo, que la prudencia mexicana se debiera a las presiones de Poinsett. Aunque el embajador estadounidense desconoce el contenido de las comunicaciones entre México y Centroamérica en el asunto de la mediación, a priori las considera dañinas para la independencia de este último país y capaces de 'afectar materialmente la balanza del poder en el hemisferio occidental.' Como resultado, se opone enérgicamente a las iniciativas mexicanas hasta finales de $1827 .{ }^{97}$

\footnotetext{
91 Michelena y Domínguez a Gual, 19 de julio de 1827. AM I, pp. 120-123.

92 Cuevas Cancino, Del Congreso de Panamá, p. 143. Larrazábal al Secretario de Estado, 29 de agosto de 1827, AG, pp. 206-207.

93 Gual al Ministro de Relaciones Exteriores, 15 de septiembre de 1827, O’LEARY, Memorias, Tomo XXIV, p. 387.

${ }^{94}$ Larrazábal al Secretario de Estado, 31 de agosto de julio de 1827, AG, p. 209. El delegado centroamericano piensa en una alternativa para salir del impasse de las ratificaciones: prorrogar el plazo de vencimiento, 'en cuyo caso quedarían en todo su vigor las bases sobre que se apoyó la reunión en Panamá. Ibidem, 31 de agosto de julio de 1827, AG, p. 208.

95 Ibidem, 31 de agosto de 1827, AG, p. 203. Larrazábal a Gual, 28 de noviembre de 1827, 'Asamblea de Tacubaya,' Colección de Manuscritos, Biblioteca Latino Americana, Universidad de Tulane, Doc. 4.

96 Larrazábal al Secretario de Estado, 19 de septiembre de 1827, AG, pp. 212-213.

97 Poinsett a Clay, 30 de diciembre de 1828, Manning, Diplomatic correspondence, Doc. 920.
} 
En diciembre de 1827 es el turno de Gual de insistir en la necesidad de una conferencia (siempre previa e informal) para 'fijar los principios con que la Asamblea Americana podría concurrir a poner un término a las calamidades que afligen a Centroamérica. ${ }^{98}$ Aunque Michelena y Domínguez renuevan su preferencia por tratar el tema en 'la Asamblea de los nuevos Estados de América, ${ }^{99}$ al final acuden al encuentro, realizado en casa de Larrazábal dos días antes de las navidades. El memorando de esta reunión es una síntesis de los problemas que pone la total ausencia de mecanismos de solución de controversias en el continente. Gual recuerda a Michelena y Domínguez que a pesar de sus advertencias, los ministros mexicanos procuraron 'no insertar cláusula alguna [en el tratado de 1823] en virtud de la cual pudiesen los aliados intervenir en sus negocios domésticos.' ${ }^{100}$

Ante la ausencia de fuentes legales establecidas que pudieran legitimar la mediación, Gual propone que ésta se solicite a la Asamblea 'suponiendo que exista dicha Asamblea' o, en su defecto, a los países representados en ella. Respecto a las instrucciones que Larrazábal había obtenido para participar en conferencias formales de mediación, Gual concede que el Gobierno de Guatemala ha allanado algunas dificultades 'aprobando la mediación y otras medidas análogas de conciliación que propusieron los plenipotenciarios de México', pero que es necesario que el Estado de San Salvador también la acepte, ya que 'es por ahora de facto un cuerpo político separado'. Con esta declaración sobre las incapacidades de la Asamblea fenece la única iniciativa de pacificación entre los aliados. ${ }^{101}$ Los ministros no volverán a referirse a los riegos de desintegración de Centroamérica y el rápido deterioro de la unión colombiana, aunque no se desconociera su gravedad.

\section{Gestiones de Guadalupe Victoria}

Hacia finales de 1827, el debate de las cámaras mexicanas se presenta dominado por los riesgos de invasión española. Larrazábal especula sobre la buena ocasión que esto representa para la reunión de Tacubaya, aunque descree de tal efecto porque el 'gobierno piensa sin duda tener en sí mismo sobrada

\footnotetext{
98 Gual a Larrazábal, 4 de diciembre de 1827. Tulane, Doc. 6.

${ }_{99}$ Michelena y Domínguez a Gual, el 20 de diciembre de 1827, Tulane, Doc. 4.

100 Memorando de la conferencia previa e informal en casa del ministro plenipotenciario de Centro América, Tulane, Doc. 9. Este señalamiento tendría que ser compartido por Larrazábal: en Panamá, los ministros mexicanos habían rechazado la solicitud centroamericana de 'someter las diferencias territoriales a la decisión’ del Congreso, precisamente por no tener un carácter arbitral. Larrazábal y Molina al Secretario de Estado, 10 de julio de 1826, AG, p. 135.

${ }^{101}$ Más tarde, el Gobierno centroamericano busca directamente la mediación de México, aunque esto ocasiona el temor de que ese país aproveche la ocasión para intervenir o anexarse partes del Istmo. Juan de Dios Mayorga a Poinsett, 18 de octubre de 1828, Ibarra a Van Buren, 3 de octubre de 1830, Manning, Diplomatic correspondence, Doc. 437 y 440.
} 
fuerza'. ${ }^{102}$ A consecuencia de los fracasos en la ratificación y la mediación confederada, así como del deterioro de su estado de salud, este ministro solicita autorización para regresar a Centroamérica. ${ }^{103}$ Gual comunica iguales intenciones a los ministros mexicanos en el encuentro del 25 de noviembre, ocasión que le sirve para anunciar oficialmente que Colombia 'ha ratificado ha tiempo lo que habíamos estipulado en el Istmo.' 104 Sorprendidos, Michelena y Domínguez invocan las dificultades políticas en las que se encuentra el país, pero aseguran que 'las comisiones [de la Cámara baja] tenían ya preparado su informe', etapa previa a su votación en el pleno.

Los anuncios de la partida de los plenipotenciarios y de la ratificación colombiana surten efecto en el Gobierno mexicano. A punto de concluir las sesiones ordinarias, Victoria remite una nota en la cual solicita al Congreso que se atienda la ratificación 'con la preferencia que estime correspondiente.'105 A esto agrega el anuncio de la partida de Gual y la advertencia de que en caso de verificarse, pondría en graves dificultades la apertura de la Asamblea. Poco recomendada por la libertad en los tiempos, la iniciativa fracasa. Convencidos de la inutilidad de su estancia en México, el primero de febrero de 1828 Gual y Larrazábal visitan por separado al Presidente Victoria para despedirse. Al término de su entrevista posponen la fecha de sus viajes ante las seguridades que les da Victoria de que 'el punto de los tratados quedaría concluido en todo el presente mes'. ${ }^{106}$ Luego de trece semanas, sin embargo, Victoria debe dirigirse a la Cámara de diputados en tono enérgico:

Es de suma necesidad la conclusión del [...] asunto de los tratados de Panamá antes de cerrarse las sesiones ordinarias del Congreso general. El decoro de la nación está altamente comprometido por haber pasado ya catorce meses del término fijado en ellos mismos para su ratificación. ${ }^{107}$

El final de esta comunicación no deja dudas sobre la prioridad de su Gobierno:

[...] me veo en el caso de suplicarle que apure cuantos esfuerzos estén de su parte para que en atención a la proximidad del término de las sesiones actuales se pase hoy mismo,

\footnotetext{
${ }^{102}$ Larrazábal al Secretario de Estado, 27 de octubre de julio de 1827, AG, pp. 216-217.

103 Ibidem, 10 de noviembre de 1827, AG, p. 218.

104 Memorando de la conferencia del día 25 de noviembre de 1827, Tulane, Doc. 3. La ratificación colombiana había sido comunicada a Larrazábal en enero del 1827 y luego a Michelena y Domínguez en abril de ese año. Larrazábal al Secretario de Estado, 31 de enero de 1827, AG, p. 168; Gual al Ministro de Relaciones Exteriores, 20 de abril de 1827, O’Leary, Memorias, Tomo XXIV, p. 382.

105 Monteros a la Cámara de Diputados, 20 de diciembre de 1827. AM I, pp. 126-127.

106 Larrazábal al Secretario de Estado, 12 de enero y 2 de febrero de 1828, AG, pp. 222-203.

107 Monteros a los diputados José M. Herrera, Ramón Pacheco y Crescencio Rejón, 10 de mayo de 1828, AM I, p. 135.
} 
si puede ser de esa Cámara a la del Senado el expediente con su extracto de discusión en el estado en que se encuentre.

A pesar de esto, el mismo día la Secretaría de la Cámara de Representantes le devuelve el texto de la Convención de Contingentes por estimar que 'no [la debe] tomar por ahora en consideración'. ${ }^{108}$ En cambio, el primero de mayo la Cámara baja aprueba el Tratado de Unión, Liga y Confederación -con exclusión del Art. 14 sobre la prohibición de las alianzas con países extranjeros sin previo acuerdo de la Asamblea. ${ }^{109}$ Si bien la Convención había sido uno de los puntos de mayor interés para los confederados, el avance en la ratificación de cualquiera de los tratados hace renacer las esperanzas. Por corto tiempo: las sesiones terminan sin que el Senado complete la ratificación. Victoria renueva su empeño y convoca a sesiones extraordinarias en julio para resolver éste y otros pendientes. Con igual tenacidad, el 28 de julio la Cámara alta desaprueba los tratados. Se argumenta sobre la inconveniencia de un acuerdo con países que sufrían cambios internos y cuyo articulado hacía referencia a ejércitos claramente inexistentes. ${ }^{110}$

\section{Conferencia de clausura del 9 de octubre de 1828}

Larrazábal, quien en agosto había decidido no utilizar la autorización que había recibido de su Gobierno para regresar a Centroamérica, ahora acelera los preparativos para el retiro de suelo mexicano. Sabedores de que se trata de una decisión definitiva, Michelena y Domínguez manifiestan su pesar y la ponen en conocimiento del ejecutivo. ${ }^{111}$ El 27 de septiembre de 1828, con nuevo presidente electo desde el primero de ese mes, Victoria insiste en su solicitud a la Cámara de Senadores. Para dar mayor peso a sus palabras, adjunta las misivas de Gual y de Larrazábal donde ambos anuncian su retiro de México, y pide:

[...] que se dé cuanto antes la resolución correspondiente, sea cual fuere, acerca de los tratados de la citada Asamblea, para que de este modo se haga por parte de México lo que le corresponde a fin de que se evite toda censura sobre su conducta en el particular. ${ }^{112}$

\footnotetext{
108 Secretaría de la Cámara de Representantes a la Presidencia, 10 de mayo de 1828. AM I, pp. 135-136. 109 Zubieta, Congresos de Panamá y Tacubaya, p. 133; Cuevas Cancino, Del Congreso de Panamá, p. 147. 110 Gual al Ministro de Relaciones Exteriores, 6 de agosto de 1818, O'Leary, Memorias, XXIV, p. 404. Cuevas Cancino, Del Congreso de Panamá, p. 148.

111 Michelena y Domínguez a Larrazábal, 12 de septiembre de 1828, AG, pp. 237-238.

112 Monteros a la Cámara de diputados, 27 de septiembre de 1828, AM I, pp. 139-140.
} 
Ante la reiterada negativa del Senado, remitida el primero de noviembre de 1828, la conciencia del fracaso cala en el ánimo del Gobierno de Victoria. ${ }^{113}$ Esta certidumbre abarca también a los ministros hispanoamericanos. Su último encuentro se realiza el 9 de octubre de 1828. Formal por primer vez, la conferencia tiene por objeto la cancelación de los esfuerzos para revivir la Asamblea americana. Gual, su convocante, propone 'concluir este desgraciado negocio con una especie de acta en que [él y Larrazábal se pongan] a cubierto de toda interpretación siniestra, luego que nos vayamos de este país'. ${ }^{114} \mathrm{El}$ evento se realiza en el domicilio del ministro colombiano en Tacubaya. Como era de esperar, se culpa de los resultados al 'poco o ningún interés que los Estados Unidos Mexicanos toman por la reunión de los Plenipotenciarios americanos en su territorio'. De esto, agrega Gual, fue tomando conocimiento prácticamente desde su llegada a Acapulco:

Desde entonces el Congreso mejicano manifestó repugnancia bastante notable a ocuparse en tan grave negocio, por más esfuerzos que hizo el Ejecutivo para que lo pusiese en estado de cumplir con unas estipulaciones autorizadas por los plenipotenciarios de estos Estados, en observación de instrucciones. Así se infringió una de las partes más esenciales de un tratado público, permitiendo transcurriese el día 15 de marzo del año pasado, en que debieron canjearse los de Panamá, sin que para ello se hubiese dado ninguna especie de explicación satisfactoria. ${ }^{15}$

Las observaciones de Larrazábal no son diferentes:

[Los hechos] lo habían convencido profundamente de que, o Méjico no tenía interés en concurrir por su parte a la realización de la Confederación americana, o repugnaba que la Asamblea se reuniese en su territorio; que cualquiera de estos extremos que fuese cierto, era en su concepto una razón suficiente para retirarse en obsequio mismo de la Confederación, porque de lo contrario era preciso que se hiciese ridículo y despreciable un proyecto tan importante, que en otro tiempo y otras circunstancias acaso se podrá renovar con mejor éxito.

En vano los representantes mexicanos alegan la existencia de una mejor disposición en las cámaras; que las modificaciones que se habían propuesto en la Cámara baja no alteraban la esencia de lo estipulado y que si estas facilidades no parecían suficientes a los delegados, podía trasladarse la sede a otro país. Gual y Larrazábal replican que ya habían recibido promesas semejantes en el pasado y que el cambio de sede 'no podía producir ningún buen efecto en estos momentos'. Ambos coinciden en la impresión de que la Asamblea no se volvería a reunir en un plazo previsible.

113 El Senado también dictamina en contra de la aprobación en la Cámara baja por considerarla inaceptable. Cuevas Cancino, Del Congreso de Panamá, p. 148.

114 Gual a Larrazábal, 5 de octubre de 1828, AG, pp. 233-234.

115 Protocolo de la conferencia final de Tacubaya, 9 de octubre de 1828. AM I, p. 143. 


\section{Epílogo}

En noviembre y diciembre de 1828, Victoria debe hacer frente a las revueltas propiciadas por los yorkinos. El Motín de la Acordada, la asonada que encabeza Guerrero, antiguo héroe de la Independencia mexicano, sume al país en la confusión y la inestabilidad. En uno de sus últimos actos de Gobierno, Victoria se dirige al Congreso el primero de enero de 1829 para informar que

La devolución por las Cámaras de la Unión de los tratados celebrados por nuestros plenipotenciarios en la Asamblea General Americana, reunida en el istmo de Panamá, y la situación respectiva de cada Estado, ha ocasionado el regreso a sus países de los ministros por las repúblicas de Colombia y Centroamérica, que han pedido, al efecto, sus pasaportes. En consecuencia, no puede por ahora la Asamblea continuar en la villa de Tacubaya. Antes de separarse dichos ministros han protestado de parte de sus gobiernos la buena disposición que les asiste para mandar a sus ministros tan pronto como sean excitados para continuar dichas sesiones en el tiempo y lugar que se convenga entre las repúblicas que deben formarla. ${ }^{116}$

Con notable simetría, el fracaso del proyecto bolivariano se acompaña de una nueva atomización hispanoamericana. En México, al intento de reconquista española de 1829 le sigue años después la separación de Texas y su anexión a Estados Unidos; esta última nación continuará con sus intervenciones en el norte de México hasta infligirle la pérdida de la mitad de su territorio en 1847. Larrazábal encuentra a su regreso a Centroamérica una federación prácticamente disuelta, en espera de su formal abrogación y sustitución por cinco pequeñas repúblicas: Guatemala, El Salvador, Honduras, Nicaragua y Costa Rica. Gual tampoco encuentra circunstancias mejores a su llegada a Colombia. Es detenido brevemente por las tropas peruanas que ocupan Guayaquil y comisionado por Bolívar para negociar un tratado de paz con el Gobierno de Lima. El final de ese conflicto no impide la división de Colombia en tres Estados: Venezuela, Nueva Granada (incorporando a Panamá hasta 1903) y Ecuador. En el sur, la guerra entre el Brasil y Buenos Aires se salda con la creación del Uruguay, la tercera y última escisión del antiguo Virreinato de la Plata después del Paraguay y el Alto Perú. Aquel a quien se considera el representante de la continuidad bolivariana, el Mariscal Antonio José de Sucre, es asesinado el 4 de junio de 1830; Bolívar, el único estadista con suficiente autoridad para revivir la Confederación, fallece el 17 de diciembre de ese año. Entre la independencia de las Provincias Unidas del Río de la Plata y el destrame de la Federación centroamericana, la América antes española se fracciona en 15 repúblicas. En aquel momento, el Congreso anfictiónico se parece más al epílogo

116 Victoria en la apertura de las sesiones ordinarias del Congreso General, $1^{\circ}$ de enero de 1829, Archivo Histórico Mexiccano (AM III), Un siglo de relaciones internacionales de México (México, 1935), p. 28. 
de la convergencia hispanoamericana que al inicio de la serie de proyectos de integración que inspirará en América Latina a lo largo de 180 años.

\section{Algunas implicaciones analíticas}

Concluida la relación del episodio de Tacubaya es necesario volver a la conjetura que ha guiado la presente sistematización de fuentes primarias y secundarias. Su tratamiento como objeto de estudio no refrenda el reduccionismo de los significados de Tacubaya al caso de Panamá. Este último estuvo enmarcado por una agenda definida y listas de instrucciones coherentes, sin escapar a los problemas interpersonales de los delegados; en Tacubaya, por el contrario, dominan los factores aleatorios, con frecuencia desligados entre sí o en contradicción. A diferencia del apoyo internacional del que beneficia la reunión del Istmo, Tacubaya ofrece el espectáculo de la plena orfandad política, teniendo como contexto el destrame del proyecto confederativo y la desaparición de la mitad de las entidades que la componen. El primer caso se presenta como un proceso más elaborado y breve, el segundo es extenso, incierto y, como lo había pronosticado Bolívar, dependiente de las particularidades mexicanas y de la ingerencia estadounidense. Estas diferencias justifican la consideración de ambas asambleas como objetos conectados, aunque analíticamente autónomos.

Recebido em 13 de janeiro de 2006 Aprovado em 15 de março de 2006

\section{Resumen}

El artículo estudia el traslado del Congreso anfictiónico de Panamá a Tacubaya y los diversos intentos de instalación de la 'Asamblea americana' en México entre 1826 y 1828. Su propósito es escalonado: primero identifica los significados decisionales relevantes para comprender el fracaso del proyecto y, enseguida, delimita la autonomía analítica del episodio mexicano del Congreso de Bolívar.

\section{Abstract}

This article studies the transfer of the Anfictionic Congress from Panama to Tacubaya and the diverse intents of installation of the 'American Assembly' in Mexico between 1826 and 1828. Its purposes are staggered: first, it identifies the decision-making meanings of the failure of the project and, then, it defines the analytic autonomy of the Mexican episode of Bolivar's Congress.

Palabras clave: Congreso de Panamá , Asamblea de Tacubaya, Gran Colombia, Simón Bolívar. Key words: Panama Congreso, Tacubaya Assembly, Great Colombia, Simón Bolívar. 